\title{
Juventud, fiesta y mercado: un estudio acerca del carnaval de Ouro Preto - Minas Gerais*
}

\author{
Sarah Teixeira Soutto Mayor ${ }^{* *}$ \\ Maria Cristina Rosa***
}

\begin{abstract}
Resumen: Este artículo pretende analizar, el proceso de mercantilización y comercialización del carnaval de Ouro Preto, Minas Gerais (MG), Brasil, en el cual la juventud y las características que le son socialmente atribuidas emergen en un escenario festivo, influenciado principalmente por la industria del entretenimiento. Para ello, se realizó un estudio del carnaval de esta ciudad del año 2009, desde un enfoque cualitativo, combinando las investigaciones bibliográfica, documental y de campo. Sin desconsiderar las múltiples posibilidades de apropiación de los sujetos en el diverso y plural tiempo-espacio de la fiesta, se identificó que las variadas formas específicas de ser joven, sus looks y estilos de vivenciar el carnaval, son el principal producto a ser vendido en el mercado de la diversión y del entretenimiento. La fiesta, que hasta hace muy poco tiempo ocurría en las calles de la ciudad, con posibilidad de participación gratuita, se transforma así en mega-producciones pagadas, privadas y destinadas principalmente al público joven.
\end{abstract}

Palabras clave: juventud, ocio, fiesta, carnaval, mercado.

\section{Youth, festivity and market: a study on Ouro Preto/MG's carnival}

\begin{abstract}
This article intends to analyze how youth and the characteristics socially assigned to them emerge in a festive scenario, very influenced by the entertainment industry, based on the commodification process of the carnival from a brazilian city, Ouro Preto, Minas Gerais (MG). For this, a study about the city's carnival was made in 2009 using the qualitative approach and combining bibliographic, documentary and field research. Without ignoring the numerous possibilities of appropriation of the individuals can have in the time-space of the festivity, which is plural, we identified youth as being the main product sold in the entertainment market, allied to specific ways of being young, to looks and styles bound to forms of experiencing carnival. The festivity, that until very recently used to happen on the streets of the city with the unpaid participation of revelers, became
\end{abstract}

\footnotetext{
* Esta ponencia es parte del texto "Ocio, mercado y cuerpo: un estudio acerca de la juventud en el carnaval de OuroPreto”, presentado al curso de Especialización en Ocio de la Universidad Federal de Minas Gerais, en el año 2009.

** Universidad Federal de Minas Gerais, Belo Horizonte, Brasil. Email: sarahtsouttomayor@hotmail.com

***Universidad Federal de Ouro Preto, Ouro Preto, Brasil. Email: m.crosa@bol.com.br
} 
a paid, private and destined to the young public super production.

Key words: youth, leisure, party, carnival, market.

\section{Juventude, festa e mercado: um estudo do Carnaval de Ouro Preto - Minas Gerais}

Resumo: Este artigo pretende analisar o processo de mercantilização e comercialização do Carnaval de Ouro Preto, Minas Gerais (MG), Brasil, em que a juventude e as características que são socialmente atribuídas a este grupo emergem em um cenário festivo, influenciado principalmente pela indústria do entretenimento. Para isso, foi realizado em 2009 um estudo de abordagem qualitativa sobre o carnaval nesta cidade, combinando as pesquisas bibliográfica, documental e de campo. Sem desconsiderar as múltiplas possibilidades de apropriação dos sujeitos no tempo-espaço diverso e plural da festa, foi identificado que as diversas formas específicas de ser jovem, seus olhares e modos de viver o carnaval, constituem o principal produto a ser vendido no mercado de diversão e entretenimento. A festa, que até recentemente ocorria nas ruas da cidade, com possibilidade de participação livre e gratuita, se transforma assim em mega-produções pagas, privadas e destinadas principalmente ao público jovem.

Palavras-chave: Juventude; Lazer; Festa; Carnaval; Mercado.

Recibido: 30.04.2010

Aceptado: 30.06.2010

$$
* * *
$$

\section{Introducción}

Este artículo tiene como principal objetivo el analizar, basados en el proceso de mercantilización y comercialización del carnaval de la ciudad de Ouro Preto, en Minas Gerais (MG), Brasil, como la juventud y las características que le son socialmente atribuidas emergen en un escenario festivo, influenciado principalmente por la industria del entretenimiento.

Como en la mayoría de las fiestas de carnaval en todo Brasil, los jóvenes, en Ouro Preto, son el interés y público principal de la industria del entretenimiento, que se consolida a cada año en la ciudad, siendo dirigidas muchas de sus propagandas especialmente a ellos. Reflexionar sobre esto es pensar acerca de la creciente inversión de capital en el mercado de las actividades de ocio, cada vez más especializadas en las variadas franjas etarias.

En Brasil, muchas fiestas y eventos, como el carnaval, fiestas funk, raves, festivales de axé y de pop-rock, shows sertanejos y gospel, componen una cultura festiva que se recicla permanentemente según modas, difundidas principalmente por los medios de comunicación y asociados a determinadas maneras de ser y de participar. Estos eventos tienen en el ideal de la juventud un gran factor de propaganda y promoción, copiando y reforzando ciertas características, como lo efímero, la permisividad, la innovación, lo instantáneo, la euforia y la irresponsabilidad. 
El mercado de las fiestas viene apostando a los sujetos jóvenes, como potenciales consumidores de manifestaciones que se valen del exceso, de la fugacidad y de la transgresión. De esa forma, la propuesta no es sólo vender aisladamente los productos, sino hacer aceptables y legítimas determinadas maneras de diversión, creando una legión de fieles consumidores de las incontables versiones que se repiten y se reciclan cada año.

El carnaval, una de las principales fiestas brasileñas, tal vez sea la que más expresa la influencia mercadológica creciente en las manifestaciones de ocio $^{1}$ para la juventud, sobrepasando, en muchas localidades, los cuatro días usuales de festividad y, cada año, ir adquiriendo nuevas formas. Por el hecho de que el carnaval se realiza prácticamente en todo el territorio brasileño, siempre surge la posibilidad de que haya exceso, de que ocurra lo impensable y de exceder los límites, como algo aceptado, más allá que el control social siga actuando, de forma mínima y sutil.

Cabe señalar que el estudio del mercado en sus relaciones con el carnaval vinculándolo con la juventud, es un tema todavía poco investigado en Brasil. Con referencia a otras manifestaciones cercanas, se encontraron investigaciones sobre las redes sociales establecidas en diversos movimientos, como el funk y el hip hop. Entre estos estudios, se destacan los de Stoppa (2005), Dayrell (2004), Magro (2002), Groppo (2002), Carrano (2001) y Dayrell y Gomes (Sin fecha) ${ }^{2}$, que investigan en las áreas de la Educación Física, la Psicología, las Ciencias Sociales y la Educación. Estos estudios hacen del ocio y de la juventud temas comunes de sus investigaciones, pero en ninguno de ellos se relacionó el ocio en su vinculación al mercado dirigido a los jóvenes, algo que cada día más se destaca en estas manifestaciones.

Sobre la presencia de los jóvenes en los movimientos de funk y hip hop, estos autores enfatizan la participación en la sociedad desde las redes de sociabilidad creadas en los grupos a que pertenecen. Considerado el carácter positivo de las experiencias de ocio de los jóvenes, comúnmente vistos como delincuentes, irresponsables o personas sin formación y a la espera de convertirse en adultos, estos estudios apuntan al ocio como la oportunidad de convertirse en “autores de si mismos” (Magro, 2002: 72), de resistir a las imposiciones de la industria cultural y a los estereotipos negativos que viven en el día a día, construyendo así procesos de autonomía y liderazgo.

Estamos de acuerdo con los autores citados, porque exponen las nuevas perspectivas para reflexionar sobre la juventud, al sugerir estudiar a estos sujetos (jóvenes brasileños) de cerca. Como señala Freitas (2006: 12), los jóvenes, cuando "son oídos, tocados y olfateados, demuestran ser

\footnotetext{
${ }^{1}$ En el artículo se usa la palabra ocio como sinónimo de la palabra lazer en Brasil.

${ }^{2}$ http://www.fae.ufmg.br/objuventude/textos/SESI\%20JUVENTUDE\%20NO\%20 BRASIL.pdf.
} 
sorprendentemente diferentes de como aparecen cuando están retratados en las estadísticas, en el imaginario social, en los diagnósticos y en los pronósticos de varias procedencias, incluidos los académicos”. Pero es necesario problematizar como la juventud y las características que les son socialmente atribuidas se convierten en productos del mercado del ocio y el entretenimiento, que valorizan y prometen cierto estilo juvenil.

Otro factor importante a considerar es que estos estudios se refieren principalmente a las posibilidades de ocio para la inclusión social de jóvenes de clase económica baja, siendo necesario, por lo tanto, investigaciones que se ocupen de jóvenes de otros estratos sociales.

Por lo tanto, tomando la fiesta como posibilidad de estudio, pensamos en jóvenes de diferentes orígenes, diferentes situaciones socioeconómicas, de varias ciudades en el país y el extranjero, que traen a Ouro Preto diversas formas de ser joven en una fiesta que también es plural. Se pueden tener, por consiguiente, nuevas perspectivas para conocer las experiencias de ocio de la juventud en el Brasil actual.

\section{Los caminos recorridos}

Para comprender la dinámica de la fiesta y cumplir con los objetivos propuestos en este estudio, se analizó el carnaval de Ouro Preto en el año 2009. La elección de esta ciudad para desarrollar la investigación, tuvo como principal motivación el hecho de que en ella está ubicada la sede de la Universidad Federal de Ouro Preto (UFOP), por lo tanto Ouro Preto cuenta con la presencia cotidiana de estudiantes (jóvenes) y con un gran número de repúblicas ${ }^{3}$. Estas casas son un territorio especial, un espacio simbólico que tiene reglas propias y bien definidas, teniendo los moradores que cumplir todo un ritual para su ingreso y permanencia, y a la vez sirven de alojamiento. Son una tradición que atraviesa generaciones, y son muy conocidas por las fiestas organizadas por sus moradores durante todo el año, especialmente en los días de carnaval.

A pesar de que el carnaval se realiza generalmente en el mes de febrero, cuando las clases en la universidad aún no comienzan, en las semanas que anteceden a la realización de la fiesta se puede observar gran movimiento de estudiantes en las repúblicas, ya que muchos de ellos participan en los preparativos de estás actividades.

\footnotetext{
${ }^{3}$ En Brasil, se llama repúblicas a las casas que sirven de residencia para los estudiantes que no son de aquella localidad donde está ubicada su universidad.

Según el sitio de UFOP, son aproximadamente trescientas cincuenta repúblicas en Ouro Preto. Es necesario considerar que muchísimas de ellas pueden no estar registradas en el sitio, lo que aumenta aún más el número (http://guiche2.ufop.br/scripts/sme/smeweb.exe/ pesquisa cidade $=1 \&$ situacao $=\mathrm{UFOP})$.
} 
Este estudio, de enfoque cualitativo, se llevó a cabo con el uso de tres tipos de investigaciones: bibliográfica, de campo y documental. La revisión de la literatura fue el primer paso y envolvió la búsqueda y selección de referencias que podrían relacionarse con el tema propuesto. Por lo tanto, contribuciones de diversas áreas que se ocupan de las temáticas relacionadas con el ocio, la juventud, la fiesta y el mercado constituyeron el marco teórico. La investigación documental se desarrollo con el fin de obtener la máxima información sobre esta fiesta. Comenzó en la Secretaría de Turismo de Ouro Preto, en los materiales impresos difundidos en la ciudad y sitios web de divulgación de los blocos, las repúblicas, de la Ilustre Municipalidad y de empresas privadas que patrocinaron el carnaval.

Los blocos son grupos de personas que se organizan para participar del carnaval en conjunto. Reúnen a la gente en torno a objetivos comunes: jugar, divertirse, compartir, distraerse, bailar, cantar, etc. Los momentos claves de un bloco son la concentración y el desfile. La concentración es el momento de la reunión de los miembros para la preparación del desfile, quienes salen por las calles de las ciudades debidamente uniformados, y con una batería ${ }^{4}$ que marca el ritmo y la velocidad del paso.

La investigación de campo tuvo como principales técnicas la entrevista semi-estructurada y la observación, lo que permitió un contacto más estrecho con el fenómeno estudiado. A principios de enero del 2009, se inició el contacto con estudiantes residentes de repúblicas, organizadores de los blocos, los funcionarios de la Municipalidad, entre otras personas y, también en otros lugares que podrían proporcionar información sobre la fiesta. La convivencia y el contacto previo fue esencial, por ayudar a identificar la forma mejor y más adecuada de realizar la observación del carnaval.

Fue escogida la técnica de observación participante, porque esta permitió un mayor contacto con los sujetos y con la fiesta misma. Dionne y Laville (1999: 178) la caracterizan como "una técnica en la cual el investigador se integra y participa en la vida de un grupo para entender su significado desde el interior." Se realizo así, la observación de diversas manifestaciones del carnaval, como concentraciones y desfiles de blocos, conciertos y fiestas en república. Según Magnani (2003), esta técnica de observación permite una mejor comprensión de los significados que los mismos sujetos incorporan, a que proporciona un contacto directo con sus acciones.

En el carnaval de Ouro Preto, en la actualidad, ocurre una oferta muy grande de atracciones. De hecho, son varios los carnavales que lo constituyen al mismo tiempo, con diferentes actividades y programaciones extensas. Conciertos, fiestas y blocos, permiten diferentes formas de participación de la juventud, lo que también es diverso y plural. Por lo tanto, para minimizar el problema de proliferación de informaciones, se seleccio-

\footnotetext{
${ }^{4}$ La batería de un bloco esta formada por un conjunto de personas tocando instrumentos de percusión que comanda el ritmo de la danza, del desfile y del caminar.
} 
naron los espacios y tiempos de investigación, en base a los datos previamente recogidos. Así, fueron elegidos: 1) la concentración de un grupo creado por jóvenes residentes de repúblicas: el Bloco Ouropirô; 2) la concentración y el desfile de un grupo creado por jóvenes residentes de la ciudad de Ouro Preto: el Bloco Diretoria; 3) las fiestas, realizadas en una república de estudiantes ${ }^{5}$.

Con características propias que confieren identidad a cada uno de ellos, coexisten los blocos de Ouro Preto: los creados por estudiantes de las repúblicas y los creados por gente de la ciudad. Las diferencias entre ellos son visibles, especialmente en la estructura y en el público. Los blocos de las repúblicas actualmente tienen el patrocinio y la colaboración de empresas privadas y su público principal son los jóvenes, lo que remite a la presencia de estudiantes universitarios. En cambio, los blocos creados por los habitantes de la ciudad no siempre dependen de la inversión externas y, aunque haya una amplia participación de la juventud, están formadas y promovidas por personas de diferentes edades.

Por la gran cantidad de blocos existentes, fueron solo elegidos Ouropirô y Diretoria (dos blocos de Ouro Preto). Ambos fueron creados por estudiantes, pero el primero estaba formado por residentes de las repúblicas y el segundo por jóvenes de Ouro Preto. Cabe señalar que este último surgió como una alternativa al carnaval de los habitantes de Ouro Preto, quienes comenzaron a percibir que la fiesta en la ciudad se enfocaba demasiado para la gente de afuera. Por lo tanto nuestra elección buscó comprender la participación de los jóvenes en estos dos contextos diferentes.

En cuanto a la república, fue elegida una en particular, donde viven once jóvenes, la cual está ubicada en el área universitaria de la ciudad, en un barrio alejado del centro histórico. La importancia de esta elección se justifica porque los residentes organizan uno de los blocos estudiados, el Ouropirô, y en esa república se hospedan personas de afuera que, además de comprar los billetes que les dan derecho a participar en el bloco -el abadá $^{6}$ - pueden comprar junto a esto el derecho de permanecer en la casa, utilizar los elementos básicos, como lugar para dormir y comida y, a su vez, pudiendo participar de las fiestas que se realizan en la casa todos los días del carnaval. Estas fiestas, que también ocurren en la mayoría de las repúblicas de Ouro Preto, garantizan, sobre todo, pequeños conciertos, bebidas y comidas para cada día de estadía.

De esta manera, intentamos comprender como la juventud en la ciudad y de la ciudad, con sus modos específicos de participar y los lugares

\footnotetext{
${ }^{5} \mathrm{El}$ nombre de la república, bien como de sus residentes que participaron en la investigación, no se divulgará, para preservar sus identidades.

${ }^{6}$ En Brasil, abadá es una camiseta que tiene el valor de billete en los shows realizados en espacios cerrados e pagados, sobretodo a la juventud.
} 
que ocupan en la escena festiva, se vincula al mercado de la fiesta, no sólo como el principal público, sino como la principal imagen a ser vendida.

\section{El mercado y la estructura de la fiesta}

En Ouro Preto, la gran estructura montada en el carnaval por organizadores de blocos, residentes de repúblicas, empresas privadas y el poder público municipal apunta al crecimiento de una industria del entretenimiento en los últimos años.

Ya en el primer contacto con la ciudad, en el carnaval del 2009, un gran cartel colocado en la entrada llamaba la atención: "Bienvenido al Skol Folia". De esta forma la fiesta ya no era el carnaval de Ouro Preto, sino más bien el de una de las principales marcas de cerveza de Brasil. Como patrocinador oficial de la fiesta, entrega la estructura necesaria que está adquiriendo el carnaval de la ciudad, lo que permite, a su vez, a las grandes empresas privadas tomar en sus manos la promoción y organización del mismo. Entre las imágenes publicitarias, se vincula un ideal de carnaval, ocio y juventud.

En las imágenes de un comercial de esa cerveza difundido por televisión durante el carnaval investigado, por ejemplo, el cuerpo fue representado como uno de los diversos productos de la fiesta, sobre todo, el cuerpo femenino, los jóvenes repetían cosas sin sentido y el carnaval era banalizado, un momento de hacer lo impensable, cosa de gente boba. La juventud y las características a ella asociada son, así, estrategias de difusión publicitaria utilizadas por la industria del entretenimiento que, de forma cada vez más creciente, apuestan al potencial mercadológico de las fiestas, valiéndose de variados esteriotipos comunes, naturalizados cada vez más en nuestro día a día.

El carnaval de Ouro Preto se ha hecho conocido nacionalmente por las manifestaciones que se producen en las estrechas y sinuosas calles de la ciudad. Pero algunas de las consecuencias de la asociación con empresas privadas se traducen en la instalación de lugares cerrados y pagados que, actualmente, ocupan una gran parte de la fiesta, que en años anteriores ocurría especialmente en las calles. Muchos blocos que hace muy poco tiempo permitían la participación gratuita ya comenzaron a cobrar entrada.

Un hito importante de las inversiones mercadológicas en el carnaval en Ouro Preto fue la creación del Espaço Folia, en el 2006. Situado en el estacionamiento del Centro de Convenciones de UFOP, es un espacio y un área cerrada con acceso restringido, bastante amplia y adecuada para la realización de grandes conciertos, contando con la infraestructura adecuada para la presentación de bandas famosas a nivel nacional. Este espacio inauguró una nueva forma de vivenciar el carnaval en Ouro Preto. Otros espacios similares están surgiendo para dar cabida a otras fiestas particulares. 
El carnaval de 2009, con el apoyo de la Municipalidad de Ouro Preto, fue organizado por empresas especializadas en la promoción de eventos. Y la DM Produções fue responsable de traer a la ciudad grandes artistas del axé y del funk, como algunas de las principales atracciones en los últimos años.

El Carnaval de Espaço Folia en casi nada se distingue de los grandes espectáculos nacionales ofrecidos a la juventud, como el Axé Brasil, que se produce todos los años en Belo Horizonte, MG. El acceso, como se hizo común en fiestas juveniles, es el abadá, la ropa que equivale a un ticket de entrada, vendida por separado para cada día del show o como un pasaporte para todos los días. Este puede ser adquirido a precios variados según los productos ofrecidos, tales como la ubicación en el auditorio, consumo de bebidas y otros.

Muchos blocos creados por los residentes de las repúblicas también comenzaron a realizar actividades en el Espaço Folia. Así, durante la noche, estaban los conciertos promovidos por DM Produções, y por la tarde, las actividades de los blocos, para lo cual era necesaria la compra y uso del abadá.

Cabe recordar que, antes de la creación del Espaço Folia, las actividades de los blocos ocurrían en calles o en las propias repúblicas. Rosa (1998), investigando las interrelaciones de los turistas y residentes, por las manifestaciones corporales del carnaval de Ouro Preto en 1997 y 1998, observó que la concentración del conocido Bloco do Caixão se realizaba en la calle frente a la república e incluía a los residentes y a otras personas de la ciudad e incluso a turistas. Era un momento de contacto social entre los participantes de blocos y de aprendizaje para los nuevos miembros de la batería.

Entre los diversos momentos del bloco, la concentración era la llegada de los ex participantes y los nuevos miembros. Comenzó alrededor de las trece horas y sobre las diecisiete horas la puerta de la república estaba llena y también la calle más cercana, por donde el bloco pasaría, la calle Paraná, con gente vestida de negro a la espera de agregarse al bloco. El contacto social se producía a través de bebidas, conversaciones informales, prueba de los toques de la batería, de pintar la cara y el cabello. Eran situaciones que generaban aproximación entre las personas de la república, invitados, visitantes, vecinos, curiosos, etc. (Rosa 1998: 115).

Actualmente, las atracciones de los blocos, con bandas de renombre, abadá colorido, promesa de seguridad, público seleccionado y la diversión asegurada, representan una fuerte evidencia del proceso de mercantilización del carnaval, dirigido especialmente al público joven, que se convierte en el principal consumidor.

Valorando la rentabilidad, actualmente la mayoría de los blocos han resumido sus actividades solamente a la concentración, que pasa a ser su 
única manifestación relacionada al carnaval. El desfile, antes común, es realizado con nueva conformación, por reglamentos creados por la Municipalidad el año 2006. Con la justificativa de la necesidad de proteger el patrimonio cultural de la ciudad ${ }^{7}$, el número de participantes que pueden desfilar como máximo en cada bloco se redujo a 2000 personas. El control de este número pasó a hacerse por medio de una etiqueta distribuida por la Municipalidad, que se debe pegar al abadá de cada participante. En caso de no cumplir esta norma la multa es cercana a 5.300 dólares para todo el bloco que tenga participantes sin esa etiqueta.

Por esta razón, la mayoría de los blocos, especialmente los organizados por los residentes de las repúblicas, pasó a no desfilar, para no perder participantes, haciendo solamente la concentración, que originalmente era el momento preparatorio al desfile, pero que actualmente, paso a el momento principal de los blocos, en que las personas se reúnen, beben, danzan, se divierten y asisten a los diversos espectáculos, generalmente realizados en locales cerrados y con entrada pagada.

En el Carnaval de 2009, el Ouropirô, con aproximadamente 2.500 personas, también realizó su concentración en un lugar cerrado, el Espaço Minas Folia ${ }^{8}$, sin desfilar por las calles, debido a que sobrepasaba el número de participantes. La Diretoria, al contrario de lo que pasó en sus primeros años de existencia, también realizó la concentración en un lugar cerrado, una escuela de la ciudad. La justificación de este cambio fue la conveniencia, la comodidad, la seguridad y la mejora en la organización. Pero hoy, la Diretoria, quien no quería dejar de aceptar sólo a las personas de la ciudad, como una alternativa de carnaval para la gente de Ouro Preto, es un bloco abierto a toda persona que compre el billete, el abadá, de manera similar a los blocos republicanos. Pero hay una diferencia importante: ellos son uno de los pocos blocos formados predominantemente por jóvenes que aún desfila. Sin embargo, es significativo que, mientras el desfile se lleva a cabo en el espacio público de la calle, este es solo una extensión del carnaval pagado, el de la concentración, ya que el desfile del bloco está rodeado de guardaespaldas y un cordón que delimita el espacio, restringiendo, aunque no impidiendo, la participación de personas sin la identificación primera del bloco, el abadá.

Aunque con algunas diferencias, esos dos blocos revelan la gran influencia del mercado de la fiesta, que cada vez más restringe la participación gratuita de las personas por las calles de la ciudad y se aproxima a la

\footnotetext{
${ }^{7}$ Ouro Preto recibió el título de Patrimonio Cultural de la Humanidad en 1980. (http:// portal.iphan.gov.br/portal/montarDetalheConteudo.do?id=12622\&sigla $=$ Institucional\&retorno=detalheInstitucional).

${ }^{8}$ Aunque el nombre sugiera la aproximación con el ya consagrado Espaço Folia, y quizás haya tenido la intención de confundir a los participantes menos atentos a los detalles, ese lugar era mucho más sencillo, recibiendo los blocos menos renombrados en el carnaval de la ciudad.
} 
nueva modalidad, predominantemente particular, en la cual lo importante es la ganancia generada con la diversión, vendida de diferentes maneras y asociadas a un estilo juvenil.

\section{Juventud y el mercado de la diversión}

La necesidad humana de diversión está actualmente asociada al uso de artefactos de todas las clases y cada vez más las experiencias están mediadas por los aparatos ofertados por el mercado (Marin, 2009). En esa perspectiva, mercancías, imágenes, comportamientos, actitudes, apariencias y estilos son vendidos por la industria del entretenimiento, sobretodo las que se destinan a los jóvenes, quienes se muestran más respectivos a las nuevas modas de la diversión.

La inversión económica en el carnaval, y también en otras fiestas, camina, así, con la creciente valoración del ocio. Por lo tanto, como señala Marcellino (2008), el ocio de ninguna manera constituye una manifestación superflua, cada vez más gana status de derecho social y rol privilegiado en relación al placer y a la calidad de vida.

Pero, si por un lado ese reconocimiento es importante para el desarrollo y promoción, individual o colectivo, por otro lado le da visibilidad al ocio en el mercado que lo produce, reapropiándose de él y resignificándolo de acuerdo con los intereses en boga. De esa manera, envuelve al comercio y a la necesidad de nuevas fórmulas de ocio, vinculadas a una moral del placer que, según Costa (2007), es una creación original de la cultura actual y es uno de los colaboradores en esta relación imaginaria que se establece entre el mercado y el consumo.

Anteriormente, el sujeto tenía su identidad fuertemente construida por una moral del trabajo. Hoy en día, la moral del placer, muy ligada a la compra de objetos y servicios que permiten, además de logros afectivos y satisfacciones sensoriales, una distinción social, adquirió centralidad en las formas de identificación personal del sujeto posmoderno. Según Hall (2005), este sujeto no tiene una identidad fija, esencial o permanente. La identidad es, pues, una celebración móvil, formada y transformada continuamente en relación con las formas en que se representa o se interpela el sujeto en los signos culturales que lo rodean. Según el autor, esta crisis de identidad es parte de un proceso amplio de cambio que está dislocando las estructuras y procesos centrales de las sociedades modernas y agitando los marcos de referencia que daban a los sujetos un anclaje estable en el mundo social. En ese sentido, el consumo es una nueva forma de referencia en la construcción de las identidades.

Como también observa Marin (2009), la esfera de la diversión desempeña cada vez más un rol de agente de cambio en los caminos de la sociedad, capaz de generar un modelo ya no más anclado en el desarrollo de fuerzas productivas, sino en el desarrollo del consumo en la esfera del 
entretenimiento. Según esa autora, las necesidades humanas de ocio y diversión son funcionalizadas y reproducidas por el comercio. El ideal del placer se asocia al consumismo, lo que apunta a la necesidad de cuestionar las formas como el mercado que se vale de la diversión y se apropia de las fiestas, sobretodo las dirigidas a los jóvenes.

Considerando que muchas son las apropiaciones de los sujetos en la dinámica de la fiesta, este trabajo pretende poner de relieve no sólo una posibilidad de ser joven y de significar la participación en la fiesta. Sino también, reconoce que muchos son los sentidos por ellos conferidos en las experiencias de fiesta, especialmente el carnaval de Ouro Preto, igual como son diversos los significados que esta manifestación de entretenimiento adquiere en la sociedad.

Es preciso considerar que los jóvenes, en su cotidiano, influenciados por los medios de sociales en que viven y por los cambios influenciados por esos espacios, construyen diferentes formas de ser joven (Stoppa, 2005). Como enfatiza Dayrell (2004: 3), no hay una juventud, sino juventudes, en plural, o sea, una diversidad de modos de ser joven que se "concretizan en las condiciones sociales (clase social), culturales (etnias, identidades religiosas, valores), de género, y también de las regiones geográficas, dentro de otros aspectos”.

Por lo tanto, en la dinámica de la fiesta, hay que considerar las posibilidades de producción y también de reproducción. Hay que considerar que, aunque los jóvenes produzcan sus propias experiencias, muchas hay que están aún fuertemente ligadas a un ideal de entretenimiento en el cual el consumo, sea como forma de identificación y diferenciación social, ya sea como medio de obtener placer y bienestar individual, se encuentra fuertemente vinculado no sólo al deseo de ser aceptado, sino también de ser visible.

La juventud y las características que culturalmente se le han asignado, como lo nuevo, lo efímero, la permisividad, la transgresión, el apego al cuerpo y al exceso, se convirtieron en factores importantes en la inversión de la industria del ocio que se está consolidando en el carnaval de Ouro Preto, de acuerdo con la tendencia de otros carnavales, fiestas y espectáculos destinados a este público.

El carácter efímero atribuido a ese momento de la vida se articula a la superficialidad de la moda. Como ha señalado Rosa (2007), varios géneros de fiestas se utilizan como una atracción para este grupo social, ya que, al igual que otras prácticas culturales, adquieren valores y características ligadas a este, como la osadía, la seducción, la disposición, el gusto por la aventura y el riesgo, la estética corporal y la búsqueda de emociones y novedades. Así, la experiencia festiva se ha revelado como el tiempo/espacio para la realización de tales deseos.

En el carnaval de Ouro Preto, además de productos materiales, se 
venden los símbolos y promesas de diversión. Los abadás crean redes de identificación, la música y coreografías suscitan características de lo instantáneo. La naturaleza transitoria vinculada a los jóvenes, lejos de ser motivo de inferioridad, en el carnaval se transforma en la fase de los sueños, de los deseos, del poder, difundida en las imágenes publicitarias. Así, la juventud se desplaza hacia este lugar simbólico y va ganando importancia.

A pesar de la devaluación de la juventud como sujeto de derechos, que se traduce en la falta de políticas públicas que garanticen el acceso a los bienes culturales y materiales, y a la falta de credibilidad debido a su forma de participación en la sociedad, la juventud hoy, en cuanto modelo cultural, se convirtió, según Kehl (2007), en un lema, un cliché publicitario, un imperativo categórico, y una condición para pertenecer a alguna elite actualizada y victoriosa. Como también observan Dayrell y Gomes (sin fecha: 1) "nunca las características y valores relacionados con la juventud, como la energía y la estética corporal o incluso la búsqueda de lo nuevo, fueron tan elogiados en un proceso que podríamos llamar de juvenilización de la sociedad”.

La juventud, de esa manera, adquiere centralidad de acuerdo con características que le son representadas e idealizadas, como modelo de belleza, salud y diversión. La supervaloración del estilo de vida joven puede contribuir aún más para el vaciamiento de la condición social, ya que refuerza la idea de una fase de transición superflua, superficial, adquirible y desechable, casi como una ropa de moda.

Margullis y Urresti (1998) observan que no todo joven posee el cuerpo legítimo, el look juvenil, patrimonio de ciertos segmentos sociales que tienen más acceso a los bienes de consumo. Pero Kehl (2007) observa que la imagen del joven consumidor difundida por la publicidad y por la televisión se refiere a la identificación de todas las clases sociales. Para Margullis y Urresti, ese estilo está dando lugar al empobrecimiento de algunos usos que "llevan a confundir la condición de juventud con el signo de juventud, convirtiendo tal condición, que depende de diferentes variables, en atributo de un reducido sector social” (1998: 50).

La búsqueda por un público específico necesario para la construcción de un estilo joven se encuentra muy fuerte en el carnaval de Ouro Preto. Atributos provisorios, como la misma juventud, además de grandes éxitos musicales en aumento en los medios de comunicación, abadás, coreografías, sonidos, imágenes, propagandas, accesorios y bebidas, construyeron la estructura de la fiesta, haciendo emerger las más diversas estrategias de marketing. El bloco Cabrobó, uno de los mayores del carnaval en la ciudad, por ejemplo, estaba vendiendo sus entradas para los shows en la concentración en el formado de box de DVD, comercializado on-line vía internet en su sitio web.

Se destaca que la utilización del sitio web fue una estrategia de casi todos los blocos de repúblicas y también del bloco Diretoria. La oferta de 
productos en la red ya comenzaba en las propagandas de los grupos, meses antes del carnaval. Muchos sitios contaban con una tienda virtual para la venta de sus abadás. Sitios llamativos y estilizados, con muchos colores, músicas, fotos y vídeos de ediciones anteriores, entre otros recursos publicitarios, garantizando la diversión. Esa inversión se justifica por el hecho de que los jóvenes "habitan masiva y efectivamente el ciberespacio" (Oliveira, 2006: 247).

Tal como recuerda Bruhns (2001), la producción de imágenes se presenta como uno de los elementos que le dan impulso a la sociedad de consumo, donde una imagen adquirida por la compra de un sistema de signos, como los ofrecidos en los sitios web de los blocos, pasa a constituir un elemento importante de auto-representación.

La apuesta de los medios de comunicación como forma para atraer al público joven tiene motivos claros. Los medios, junto con el consumo de bienes y servicios, son responsables, en gran medida, por la formación de identificaciones sociales, principalmente de identidades juveniles. Como observa Canclini (2006), las identidades se configuran en el consumo, dependiendo de aquello que se posee o de aquello que se puede llegar a poseer. El autor también destaca que, en el periodo actual, muchas preguntas propias de los ciudadanos reciben respuestas más por el consumo privado de bienes y servicios que por las reglas abstractas de la democracia o por la participación colectiva en espacios públicos.

Las principales formas de propaganda del bloco Ouropirô, durante el período que precedió y en el que se investigo el carnaval de Ouro Preto, fueron carteles, panfletos y otros, especialmente en su sitio en internet. Estilizada con colores amarillo, rojo y naranja, en tonos bastante llamativos, presentaba las informaciones necesarias para el conocimiento del bloco y la adquisición del abadá. Contenía fotos y vídeos de carnavales anteriores y la referencia a un estilo propio de participar en la fiesta, explotada en el siguiente eslogan, presente también en los carteles y panfletos: “carnaval republicano”. Confiere, así, un status al que se conecta al ambiente de las repúblicas con una identificación de la principal expresión propia de juventud de Ouro Preto, la cual no se limita sólo al carnaval.

Con un diseño cuidadosamente pensado para la juventud, el sitio del bloco Diretoria utilizó otro recurso, utilizado por algunos blocos republicanos: la música. Al acceder a la página, la persona que buscaba informaciones se encontraba con uno de los éxitos del axé reproducido por la banda Beat Bom, atracción ofertada por el bloco, anticipando así el clima de la fiesta que se buscaba anunciar. De esa forma, el interesado ya tenía contacto con uno de los productos ofertados.

Tal como los blocos, la república investigada también invirtió mucho en la propaganda de su carnaval. Un sitio web muy llamativo, con fuerte apelo visual percibido en el estilo de las letras, en los diseños y en los colores fuertes, las atracciones organizadas para cada día, la cantidad de 
bebida, la exaltación de la infraestructura, tal como fotos y vídeos de carnavales anteriores, componían las principales formas de propagandas de la casa.

Se creaba, así, un universo simbólico de pertenencia a un mundo exclusivamente joven. El esquema de valores que reproducían formas de participar de la fiesta estaba ligado a la adquisición de productos vendidos/ consumidos. "Una lógica del consumo que apunta hacia los modos socialmente estructurados de utilizar bienes para demarcar relaciones sociales" (Featherstone, 1995: 35) y que posee una función de intercambio social, configurándose en una "búsqueda incesante por la satisfacción de las necesidades emocionales de los individuos” (Freitas y Oliveira, 2004: 48).

Werneck e Isayama (2001: 54) recuerdan que "la juventud representa hoy un tema fundamental para la cultura del consumo, bien como el culto a la buena forma, a la belleza, a la aventura y al erotismo, entre otros”. Para Featherstone (1995), el placer que se obtiene con la compra de esas formas de identificación, resultado de la manipulación realizada por la publicidad de los anunciantes o de la obsesión por el status social, es un gozo ilusorio estimulado por la fantasía.

El look joven, aliado a un estilo, citado por Argulis y Urresti (1998), se convierte en una mercancía que no se relaciona necesariamente a la condición social que la juventud representa, sino a una serie de características, atributos y formas de ser, fuertemente asociadas al poder de consumo. Vendidas y consumidas en la fiesta, se traducen en formas de diversión idealizada.

El valor implícito de adhesión de los blocos del carnaval, del hospedaje en las repúblicas, de la compra de imágenes, sonidos, ropas, accesorios y fiestas etc., vehiculado como expresión del deseo de inclusión y visibilidad, se concentra menos en la utilidad práctica de esos artefactos y más en su valor de lenguaje capaz de comunicar la adhesión a un grupo de interés. Según Baudrillard (2007: 78), "las conductas de consumo, aparentemente orientadas y dirigidas hacia el objeto, corresponden en realidad [...] a la expresión metafórica desviada del deseo, a la producción por medio de signos diferenciales de un código social de valores”.

Merengué (2002: 59) también señala para ese valor que el consumo adquiere. Para él, "la idea de consumo, mucho más que la adquisición de bienes materiales, se extiende al comportamiento, a la actitud, a la subjetividad [...]. Consumir, adquirir, incorporar, pasan a significar ser un individuo". Un ejemplo de esa otra función del consumo se podía observar durante la fiesta en Ouro Preto. Algunos días antes del inicio de las actividades de los blocos, varias personas ya transitaban por las calles con abadás fosforescentes, de ese año o de anteriores. Y en el Miércoles de Ceniza, día en el cual ya no existe ninguna de las manifestaciones estudiadas en este trabajo, varias personas dejaban la ciudad vestidas con sus abadás. 


\section{Un carnaval hecho de jóvenes para jóvenes}

Un punto importante a ser destacado es que el emprendimiento mercadológico presente en el carnaval consideraba a la juventud como su mayor inversión, lo que también es realizado, en gran parte, por jóvenes, lo que nos permite reflexionar acerca de ciertos aspectos de la nueva relación que se establece entre juventud y mercado, pero ya no de manera unilateral, ni lineal, como si los sujetos fueran únicamente influenciados por el mercado, sin interactuar con él.

Con los altos precios cobrados en el hospedaje de los participantes, tal como en la república investigada, donde se llegaba a cobrar aproximadamente 300 dólares por los cuatro días, y con la inversión en las concentraciones de los blocos, los residentes de las repúblicas recaudaron significativos ingresos económicos, los cuales se utilizan, principalmente, en el mantenimiento de la casa durante todo el año. El conjunto de servicios y actividades vendidas por la república investigada incluía la participación en el bloco, liberación de cerveza en todos los días de carnaval, participación en las fiestas, además de desayuno y almuerzo y lugar para dormir.

Para atender a la estructura ofertada a un gran número de personas, los residentes hacían turnos de trabajo, como funcionarios de un hotel. Por ejemplo: el sábado de carnaval un residente quedaba como responsable por el desayuno, otro por el almuerzo, otro por la fiesta que se realizaría en el día, otro por la limpieza, otro por la seguridad, etc. Cuando no estaban trabajando, quedaban libres para disfrutar el carnaval, pero, al final, todos se hacían responsables por alguna cosa, debido a la gran cantidad de quehaceres. Respecto a esas responsabilidades, uno de los residentes hizo el siguiente relato:

Durante el carnaval se hace un listado de tareas [...] todos los días. Una vez cumplida su labor, el residente queda liberado del servicio en aquel día, pero siempre recordando que, aún que esté libre, sigue existiendo la república como tal, que tiene que tener la atención de todos (Residente de la república, 2009).

La vinculación con el hospedaje durante la fiesta se carga de una intención que, según los mismos moradores, es generar ganancias para mantener a la república. Ellos buscan reunir fondos para mantener la casa durante todo el año y lograr, en el futuro, adquirir una casa propia, pues que la actual es alquilada. Por eso, el carnaval es también un momento de trabajo colectivo.

Otro bloco de la ciudad, el Mesclado, uno de los incontables blocos republicanos, dejó evidente en su sitio web el objetivo principal de conseguir ingresos económico para la casa, señalando la siguiente idea en relación al carnaval: “contribuirá para la manutención de la estructura física de las repúblicas estudiantiles tradicionales de Ouro Preto, a través de la aplicación de recursos obtenidos con sus actividades" (www.blocodomesclado. 
com). De esa manera, la fiesta también se configura como una de las formas de obtención de recursos financieros para mantener a los estudiantes en la ciudad. Por lo tanto, el aumento de los blocos republicanos, en los últimos años, puede haber sido motivado por ese retorno financiero. En el carnaval de Ouro Preto de 1997, investigado por Rosa (1998), constaban en la programación cinco blocos republicanos. Hoy, según la Secretaría de Turismo de Ouro Preto, son más de cuarenta. Así, el carnaval, para los organizadores de esos blocos, se convirtió en un atractivo negocio.

Asociada a las normas municipales y al potencial lucro posibilitado por la fiesta en Ouro Preto, la concentración tomó la antigua centralidad del desfile, como ya se ha dicho, pasando a constituirse en el principal momento de los blocos, realizado en lugares cerrados y cada vez más estructurados para atender una demanda creciente de participantes.

Sin embargo, el desfile, abandonado por la mayoría de los blocos, se tornó atractivo de algunos blocos que optaron por mantenerlo en la programación, destacándolo en su propaganda, en los sitios web y en el material impreso. Por ejemplo: “tradicional desfile por el centro de la ciudad”, era, así, una nueva forma de promoción.

La Diretoria y los otros blocos que utilizan esa propaganda buscan una revalorización del desfile, como algo que era una tradición de la ciudad, pero que, por se estar perdiéndose con la nueva conformación del carnaval, se convirtió en una novedad. Baudrillard (2007), al problematizar la tendencia de las personas a valorar y enaltecer lo que se encuentra fuera de circulación, dice que los turistas consumen bajo forma ritual lo que ya fue acontecimiento histórico, reactualizadolo por fuerza, casi como una leyenda. Según ese autor (2007: 103), se consume también el placer simultáneo, mixto y cómplice del objeto o de la situación y de los prestigios fallecidos de todo aquello cuya muerte es significada por ellos y también por ellos resucitada.

El desfile de los blocos parece, así, haber adquirido más importancia después de su efectiva pérdida, posibilitando la adquisición de placer y prestigio, lo que denota diferenciación para quienes participan, tal como los otros objetos adquiribles en el mercado de la fiesta.

\section{Consideraciones finales}

Se puede concluir, por las observaciones y entrevistas, como el carnaval investigado en Ouro Preto está relacionado con el mercado del ocio y el entretenimiento que se ha instalado y viene creciendo en la ciudad en los últimos años. Con el apoyo de la Municipalidad, se están instalando lugares cerrados para realizar fiestas importadas de otros contextos nacionales. El tradicional e irreverente carnaval, que hace muy poco tiempo ocurría predominantemente en las calles de la ciudad, de forma diversificada y que involucraba a las personas por la variedad de manifestaciones culturales, 
teniendo el escenario barroco de la ciudad de fondo y con participación gratuita, se está convirtiendo en una mega-producción pagada y destinada predominantemente al público joven y, especialmente, con dinero.

Un punto importante es la adhesión a esos modelos por los mismos jóvenes que participan en la organización, con intenciones bien definidas hacia la posibilidad de generación de ganancias. El mercado, en ese sentido, no posee una actuación vertical, unilateral, ejerciendo simplemente el poder de consumo sobre los sujetos. Se verifica incluso una interacción y una conexión entre el mercado y los jóvenes organizadores del carnaval, que encuentran así medios de ganar dinero, ya sean estudiantes residentes de las repúblicas o residentes de la ciudad, como demostraron los organizadores del bloco Diretoria, cuyo objetivo era, inicialmente, solamente reunir personas de la ciudad.

Al mismo tiempo, los jóvenes que vienen para participar de la fiesta, vivencian esa manifestación cultural como un producto o una fiesta de carnaval cualquiera, muchas veces desconectada del escenario local y de las peculiaridades que el proporciona.

La conformación actual del carnaval de Ouro Preto proporciona algunos elementos importantes para pensar la fiesta y, con eso, también otras manifestaciones de ocio, por ejemplo, el desplazamiento progresivo del carácter público de las festividades para lo privado y la juvenilización de la fiesta, pues casi todos los atractivos pasan a ser enfocados especialmente para el público joven, lo que puede ocasionar una participación menor de personas de otras franjas etareas y con otros intereses. También se observa la pérdida del carácter propio de la fiesta, que está conectado a las tradiciones de la ciudad y a las experiencias de los sujetos, construidas a partir de la diversidad, así como una reproducción y una afirmación de un modelo de fiesta nacional.

La utilización de abadas por los participantes, el patrocinio de grandes empresas, la realización de grandiosos espectáculos cerrados y pagados con bandas famosas que tocan diferentes ritmos de moda, como axé y funk, así como, los desfiles de los blocos que, aunque ocurran en espacios públicos de la calle, pasan a ser también cerrados y pagados, son características, entre otras, que recuerdan, especialmente, al carnaval de la ciudad de Salvador, promocionado por los medios de comunicación como uno de los principales modelos de carnaval en Brasil y que posee un claro carácter no abierto, ni gratuito y con una amplia inversión de empresas privadas.

Para estas grandes empresas privadas que pasan a organizar y promover manifestaciones de ocio y entretención, incluido el carnaval, poco les importa la igualdad de acceso para los sujetos participantes de la fiesta y, menos aún, la valorización de las costumbres o tradiciones locales. Al contrario, es preciso transformar la fiesta de acuerdo con los símbolos de la moda para venderla al mayor número de personas de diversas regiones del país, especialmente al público joven, un consumidor potencial. 
¿Pensando el carnaval de Ouro Preto, qué justifica, entonces, su formato actual con abadás, conciertos en lugares cerrados, blocos que se resumen a concentraciones y predominancia de manifestaciones para el público joven? ¿ Será que, con tal conformación, los blocos organizados por estudiantes moradores de repúblicas o por personas de la ciudad consiguen aún promover un carnaval también para personas del propio territorio? ¿Qué nuevo modelo de carnaval está surgiendo y afianzándose en ciudad?

Todas estas preguntas nos hacen reflexionar acerca del potencial que posee el mercado en el intento de homogenizar las manifestaciones de ocio $_{2}$ en este caso las fiestas de carnaval de Ouro Preto, para venderlas como un producto. Es muy decidor el que la expresión Skol Folia, presente en un gran cartel en la entrada de la ciudad, en cuanto publicidad de una marca de cerveza difundida en los medios de comunicación, a su vez estaba también en las concentraciones del bloco Diretoria y en Espaço Folia .

Uno de los fuertes indicios de la mercantilización de la fiesta de Ouro Preto es el crecimiento del número de blocos formados por estudiantes residentes de repúblicas, hecho especialmente significativo en la última década. Como estrategias de ese negocio que se expande, la tradición de la fiesta de la ciudad se vendió con el formato actual de los abadás instaurado en la ciudad. Jóvenes republicanos venden el carnaval de sus repúblicas y de sus blocos con los vínculos a una tradición de viejos tiempos, reinventada y reescrita para agregar valor a sus manifestaciones/productos. Se vende una tradicional fiesta particular, cerrada y pagada, que se consolidó a lo largo de los años en las calles con la participación gratuita.

Sin embargo, no se pretende entender el consumo como lugar sin escapatoria de alienación y reproducción ${ }^{9}$, sino que buscar comprender al mercado joven que se está instalando en Ouro Preto. No se problematiza la alteración de la fiesta, a lo largo de los últimos años, como aniquiladora de una cultura original (Magnani, 2003), sino sus intereses y significados actuales.

Es cierto que las transformaciones son parte del proceso de re-creación constante de la cultura en la cual las costumbres se insertan y también se transforman, continuamente. Como señala Hobsbawm (1997: 10), "las costumbres no se pueden dar la indulgencia de ser invariables, ya que la vida no es así ni siquiera en las sociedades tradicionales”. Pero en el proceso continuo de transformación al cual está sometida la cultura, y con eso el mismo carnaval, es necesario comprender los significados que adquiera la fiesta. Como estudiosos del ocio, es necesario que nos pongamos en continuo ejercicio de desconfiar de las transformaciones emprendidas por el

\footnotetext{
${ }^{9}$ Canclini (2003, p. 71) señala: “podemos actuar como consumidores situándonos en los procesos de interacción que el mercado regula, como también podemos ejercer como ciudadanos una reflexión y una experimentación más amplia, que tenga en cuenta las múltiplas potencialidades de los objetos, que aproveche su 'virtuosismo semiótico', en los variados contextos en que las cosas nos permiten encontrar a las personas”.
} 
mercado y de pensar cuáles variados significados está asumiendo el ocio, y a cuáles intereses está ligada su promoción.

De esa manera, se vuelve fundamental problematizar estas relaciones en la construcción del carnaval de Ouro Preto y las formas por las cuales se promueve y se vehicula para una juventud idealizada y cómo viene sirviendo a las ganancias de emprendimientos privados. Se torna esencial pensar en los sentidos que ese carnaval, moldeado por el mercado que se especializa en la diversión para los jóvenes, adquiere para los sujetos, jóvenes o no, que participan de esa festividad.

Algunas indicaciones pueden ser destacadas en esta investigación, como el buscar experiencias de ocio efímeras y satisfacción de un placer momentáneo sin una conexión más sólida con las personas, ni con el lugar.

Para una juventud que creció con la obligación de "gozar más” que, según Kehl (2007), es un imperativo de disfrutar de la vida, un deber de la felicidad y una obligación de la libertad, de este modo, lo que parece importar es la diversión a cualquier costo. Situaciones y sensaciones, anunciadas y prometidas por el mercado en las extensas programaciones de shows que llenan todos los días festivos de los participantes/consumidores, acompañados por la bebida, legitimada por el principal patrocinador de la fiesta, como el principal combustible para alcanzar la euforia deseada en los días del carnaval. Esta euforia y descontrol se refiere especialmente al comportamiento que se espera del joven en ese y en otros momentos festivos.

De esta investigación surgen otras interesantes temáticas para ser desarrolladas en trabajos futuros como, por ejemplo: ¿Qué representa para la sociedad actual el ocio unido al consumo, cuyas experiencias son mediadas cada vez más por el dinero, y muchas veces apoyadas por el poder público, el que debería garantizar los intereses de toda a población? ¿Qué significados el ocio adquiere en esta producción en serie de fiestas y, posiblemente, en otras manifestaciones reconocidamente lucrativas e destinadas a la juventud? ¿Cuál es el nuevo ideal de ocio que emerge en este proceso y que es lo que puede ser problematizado en relación a sus conceptos actuales, ya que cada vez más el factor económico es puesto como condición para la efectiva vivencia de sus manifestaciones? ¿Qué nos puede indicar todo esto de los nuevos vínculos que se establecen entre fiesta, ocio, mercado y empresa privada?

Tal como se ha mencionado a lo largo de este trabajo, la juventud, como la fiesta, es plural, diversa y significa o re-significa el carnaval de incontables maneras, muchas de las cuales se pueden mostrar muy distintas de lo que se señaló en esta investigación. Pero, sin duda, la fuerte influencia de la industria del ocio y el entretenimiento, así como, la adhesión de los jóvenes que sienten representados por la propaganda de la cervecera patrocinadora de la fiesta, por el axé y por el funk del momento, por las imágenes publicitarias y por un universo simbólico cuidadosamente proyectado para insertarlos en el mercado de la diversión y en gran medida también en el mercado de la alienación. 
Polis, Revista de la Universidad Bolivariana, Volumen 9, $N^{\circ}$ 26, 2010

\section{Bibliografía}

Baudrillard, J. (2007), A sociedade de consumo, Lisboa.

Bloco Cabrobró (2009), Disponible en: www.blococabrobro.com.br. Acceso el: 05/02/2009.

Bloco Diretoria (2009), Disponible en www.blocodiretoria.com.br. Acceso el: 05/02/2009.

Bloco Mesclado. (2009), Disponible en: www.blocomesclado.com.br. Acceso el: 05/02/2009.

Bloco Ouropirô (2009), Disponible en: www.blocoouropiro.com. Acceso el: 05/02/2009.

Bondia, J. (2002), "Notas sobre a experiência e o saber de experiência”, en: Revista Brasileira de Educação $N^{\circ} 19$, Campinas.

Bruhns, H. (2001), "Reflexões sobre a relação entre lazer e consumo”, en: Isayama, H.; Werneck, C., Coletânea do II Seminário "O lazer em debate”, Belo Horizonte, Universidade Federal de Minas Gerais, p.18-25.

Canclini, N. (2006), Consumidores e cidadãos: conflitos multiculturais da globalização, Rio de Janeiro.

Carrano, P. (2001). “Os jovens e a cidade”, en Trabalho e sociedade, Rio de Janeiro. Disponible en:<http://www.uff.br/obsjovem/mambo/ index.php?option=com_docman\&task=cat_view\&gid=20\&Itemid=32> Acceso el: 18/06/ 2009.

Costa, J. (2007), “Perspectivas da juventude na sociedade de mercado”, en Novaes, R.; Vannuchi, P. Juventude e sociedade: Trabalho, educação, cultura e participação, São Paulo, p. 75-88.

Dayrell, J. (2004), “Juventude, grupos culturais e sociabilidade”, en Observatório da juventude. Disponible en: <http://www.fae.ufmg.br/ objuventude/textos/ABA2004.pdf> Acceso el: 18/06/2009.

Dayrell, J.; Gomes, N. (sin fecha.), “A juventude no Brasil”, en Observatório da juventude. Disponible en: <http://www.fae.ufmg.br/objuventude/textos/SESI\%20JUVENTUDE\%20NO\%20BRASIL.pdf> Acceso el: 18/06/ 2009.

Dionne, J.; Laville, C. (1999), A construção do saber: manual de metodologia da pesquisa em ciências humanas. Porto Alegre; Belo Horizonte.

Featherstone, M. (1995), Cultura de consumo e pós-modernismo, São Paulo. 
Freitas, M. (2006), “Observatórios da infância e da juventude”, en Freitas, M. (Org.). Desigualdade social e diversidade cultural na infância e na juventude, São Paulo, p. 7-14.

Freitas, R.; Oliveira, J. (2004), “Verbete Consumo”, en Gomes, C. (Org.). Dicionário Crítico do Lazer, Belo Horizonte, p. 48-50.

Groppo, L. (2002), “A emergência da juventude e do lazer como categorias socioculturais da modernidade" en Licere $N^{\circ} 1$, Revista da Universidade Federal de Minas Gerais, Belo Horizonte, p. 73-82.

Hall, S. (2005), A Identidade cultural na pós-modernidade, Rio de Janeiro.

Hobsbawm, E. (1997), "Introdução: A invenção das tradições”, en Hobsbawm, E; Ranger, T. (Orgs.). A invenção das tradições, Rio de Janeiro.

Isayama, H.; Werneck, C. (2001), "Lazer, cultura, indústria cultural e consumo”, en Isayama, H.; Stoppa, E; Werneck, C., en: Lazer e mercado, Campinas.

Kehl, M. (2007), “A juventude como sintoma da cultura”, en Novaes, R.; Vannuchi, P. Juventude e sociedade: Trabalho, educação, cultura e participação, São Paulo, p.89-114.

Ludke, M.; André, M. (1986), Pesquisa qualitativa em educação: abordagens qualitativas, São Paulo.

Magnani, J. (2003), Festa no pedaço: cultura popular e lazer na cidade, São Paulo.

Magro, V. (2002), “Adolescentes como autores de si próprios: cotidiano, educação e o hip hop”, en Caderno Cedes V.22, N.57, Campinas. Disponible en: < http://www.cedes.unicamp.br> Acceso el: 04/02/2009.

Marcellino, N. (2008), “Apresentação”, en Marcellino, N. (Org.). Lazer e sociedade: múltiplas relações, Campinas.

Marin, E. (2009). "Entretenimento: uma mercadoria com valor em alta", en Movimento V.15, $N^{\circ} 2$, Revista da Universidade Federal do Rio Grande do Sul, Porto Alegre.

Margullis, M; Urresti, M (1998), “La construcción social de la condición de juventud”, en Margullis et al. Viviendo a toda: jóvenes, terristorios culturales y nuevas sensibilidades, Bogotá.

Merengué, Devanir ( 2002) , “A ordem e o mercado dos prazeres”, en: Bruhns, H; Gutierrez, G. (orgs.). Enfoques contemporâneos do lúdico. Campinas, p. 57-70. 
Ministério da Cultura; Instituto do Patrimônio Humano e Artístico Nacional (IPHAN). Brasil. Disponible en: http://portal.iphan.gov.br/portal/ montarDetalheConteudo.do?id=12622\&sigla=Institucional\&retomo=detalheInstitucional. Acceso el: 27/09/2009.

Oliveira, R. (2006), “Culturas juvenis na metrópole: cultura audiovisual, formas de expressão e consumo simbólico.”, en Freitas, M. (Org.). Desigualdade social e diversidade cultural na infância e na juventude, São Paulo, p.244-258.

Rosa, M. (1998), Inter-relações de turistas e moradores: um olhar através das manifestações corporais no carnaval de Ouro Preto. Dissertação de Mestrado em Educação Física, Faculdade de Educação Física, Universidade Estadual de Campinas, Campinas.

Idem (2007), “As festas e o lazer”, en Marcellino, N. Lazer e cultura, Campinas.

Stoppa, E. (2005), “Tá ligado mano”: o hip hop como lazer e busca da cidadania. Tese de Doutorado em Educação Física, Faculdade de Educação Física, Universidade Estadual de Campinas, Campinas.

Universidade Federal de Ouro Preto. Disponible en: http://guiche2.ufop.br/ scripts/sme/smeweb.exe/pesquisa?cidade=1\&situacao=UFOP. Acceso el: 10/01/2009. 